\title{
A Comparative Study of the Correlation of Seasonal and Diurnal Cycles of Transhorizon Radio Transmission Loss and Surface Refractivity
}

\author{
B. R. Bean ${ }^{1}$, L. Fehlhaber ${ }^{2}$, and J. Grosskopf ${ }^{2}$
}

(Received April 12, 1962)

\begin{abstract}
Correlations between the surface refractivity, $N_{s}$, and transhorizon recordings of VHF radio transmission loss are examined for 34 U.S. and 9 German radio paths. The largest correlations are found to be associated with the seasonal cycle of nighttime recordings and diurnal cycles during the summer months. The annual cycles may be represented by a single regression coefficient of $-0.18 \mathrm{db} / N_{s}$ for either night or day. The regression coefficients for the diurnal cycles lie between -0.2 and $-1.1 \mathrm{db} / \mathrm{km}$ and vary with distance and season, being greatest between 175 and 200 kilometers and in the winter months. A promising method of estimating the within-month distribution of hourly median transmission loss is suggested by combining the seasonal and diurnal correlation analysis. It is indicated that $N_{s}$ provides as useful a prediction of diurnal and seasonal variations of monthly median values of transmission loss as radio measurements made over the actual radio path in previous years.
\end{abstract}

\section{Introduction}

Radio physicists have long sought a dependable relationship between recorded transhorizon transmission loss and atmospheric properties. The surface value of the radio refractivity at midpath, $N_{s}$, has received much study. Pickard and Stetson [1950a, b] noted a strong correlation between monthly median values of both variables. Bean [1956] found that this correlation deteriorated with decreasing averaging time, being about 0.9 for monthly averages, 0.7 for 5 -day averages and 0.5 for daily averages. Further studies have shown a high degree of correspondence between hour-to-hour variations of transmission loss and median scale weather events [Moler and Arvola, 1956; Moler and Holden, 1960]. To date the practical application of radio meteorological correlation has been to predict the path-to-path, or geographical variation of long-term transmission loss. The present study is directed towards estimating the variation of hourly median transmission loss over individual paths.

All of the above climatic studies are concerned with correlation of annual cycles as this paper will also be. However, the correlation of diurnal cycles will also be investigated with a view towards estimating the within-month variation of transmission loss.

\footnotetext{
1 Central Radio Propagation Laboratory, National Bureau of Standards, Boulder, Colo.

2 Fernmeldetechnische Zentralamt, Darmstadt, Germany.
}

\section{Radio and Meteorological Data}

Hourly median transmission loss values were examined for the 34 different U.S. and 9 German stations listed in appendix 1 . In general the data for each propagation path are recorded for at least $2 \mathrm{yr}$ and a minimum of $8 \mathrm{hr}$ per day. Monthly median values of transmission loss, $L_{b}$, were prepared for each hour of the broadcast day for each month.

Both seasonal and diurnal trends were immediately apparent in these monthly medians. Figure 1 gives examples of these trends for two stations, WCSIFM, path number 11 (Columbus, Indiana-Urbana, Ill.) and KIXL-FM, path number 3 (Dallas-
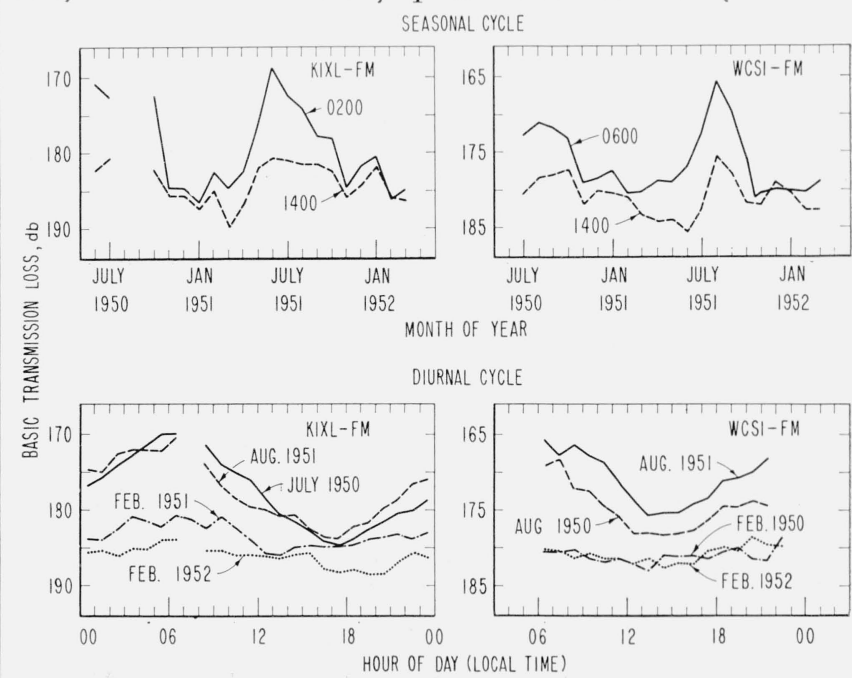

FiguRe 1. Examples of seasonal and diurnal cycles of monthly median transmission loss. 
Austin, Tex.). A consistent pattern was found on all such data plots. The seasonal cycle for the nighttime and early morning hours is much more pronounced than for the midafternoon hours. Midafternoon, however, appears to have more nearly uniform propagation conditions throughout the year. It appears quite significant that the diurnal cycles are so similar year-to-year rather than month-tomonth within the same year. This last observation dominates the analysis of this paper. First, correlation of monthly median diurnal and seasonal cycles will be derived. Second, the statistics of these correlations will be analyzed, trends deduced and, third, these trends will then be applied to the analysis of hour-to-hour variation of transmission loss within the month.

Using standard statistical techniques, the correlation of seasonal cycles of monthly median transmission loss with monthly average values of the surface refractivity, $N_{s}$, were derived. At first sight these correlations had no discernible pattern. It seemed advisable to examine these correlation coefficients in terms of some pertinent measure of propagation characteristics. The standard deviation of the measured transmission losses, $s\left(L_{b}\right)$, was used as such a measure. The correlation coefficients of seasonal and diurnal cycles are shown on figures 2 to 5 . The average correlation coefficient was estimated through the use of Fisher's z [Snedecor, 1946] applied within small intervals of $s\left(L_{b}\right)$. Prior to the analysis it was decided to give no weight to the correlations associated with $s\left(L_{b}\right)<2 \mathrm{db}$ since this represents the opinion of the International Consultative Committee for Radio (CCIR) [1959a] as to the order of magnitude of the error of measurement of $L_{b}$. One reaches several conclusions from

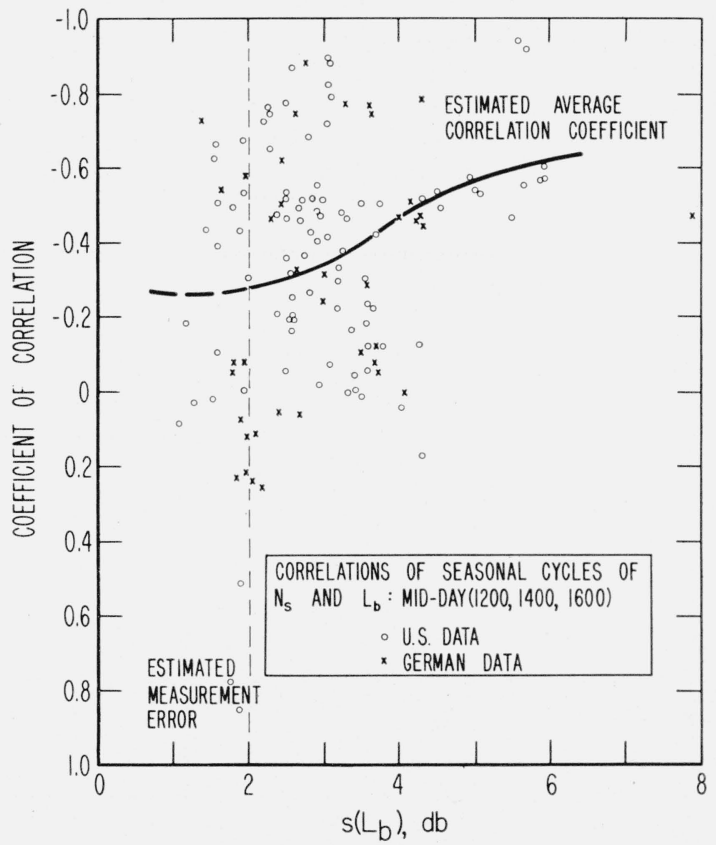

Figure 2. Correlation coefficients of seasonal cycles of $\mathrm{N}_{\mathrm{B}}$ and $\mathrm{L}_{\mathrm{b}}$ : midday $(1200,1400,1600)$ versus the standard deviation of $\mathrm{L}_{\mathrm{b}}$. figures 2 to 5 . The correlation coefficients appear to scatter to the point of insignificance within the region $s\left(L_{b}\right)<2 \mathrm{db}$. Of course the correlation coefficients are systematically greater the more $s\left(L_{b}\right)$ exceeds $2 \mathrm{db}$. It follows, then, that the largest correlation coefficients are found with the most pronounced cycles of transmission loss; i.e., the seasonal cycle

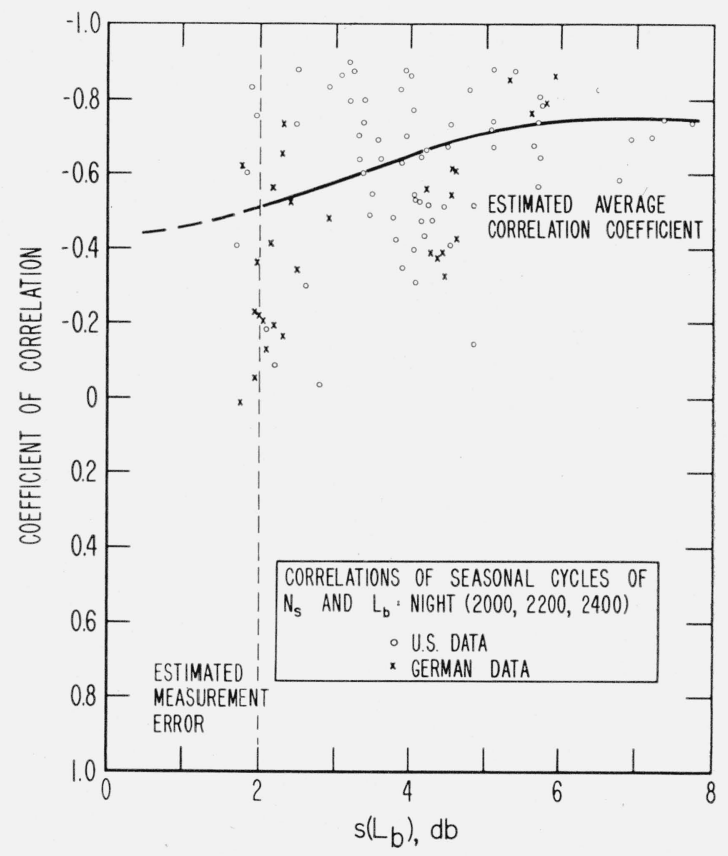

Figure 3. Correlation of coefficients of seasonal cycles of $\mathrm{N}_{\mathrm{s}}$ and $\mathrm{L}_{\mathrm{b}}$ : night (2000, 2200, 2400) versus the standard deviation of $\mathrm{L}_{\mathrm{b}}$.

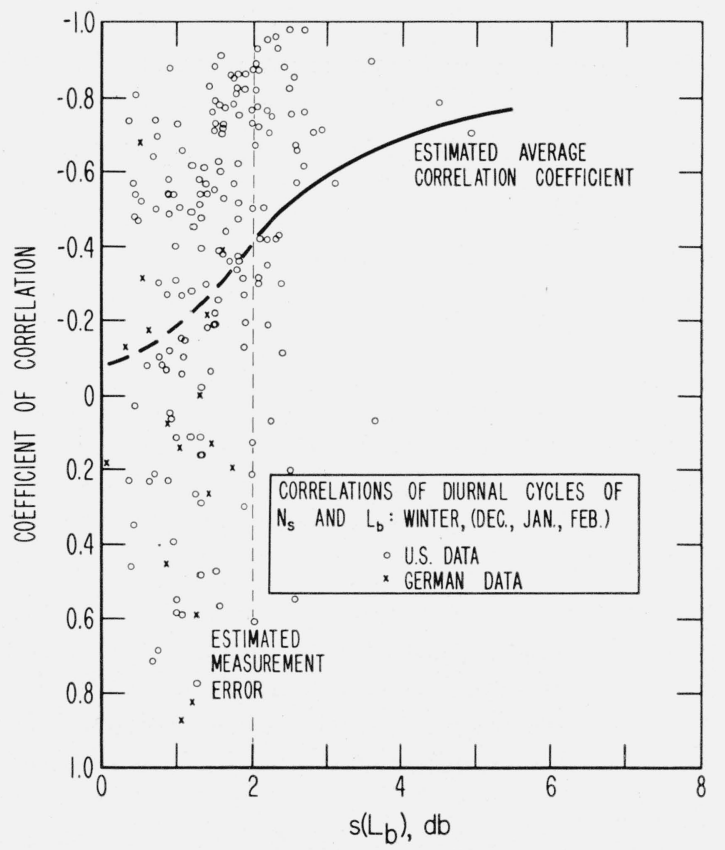

Figure 4. Correlation coefficients of diurnal cycles of $\mathrm{N}_{8}$ and $\mathrm{L}_{\mathrm{b}}$ : winter (Dec., Jan., Feb.) versus the standard deviation of $\mathrm{L}_{\mathrm{b}}$. 


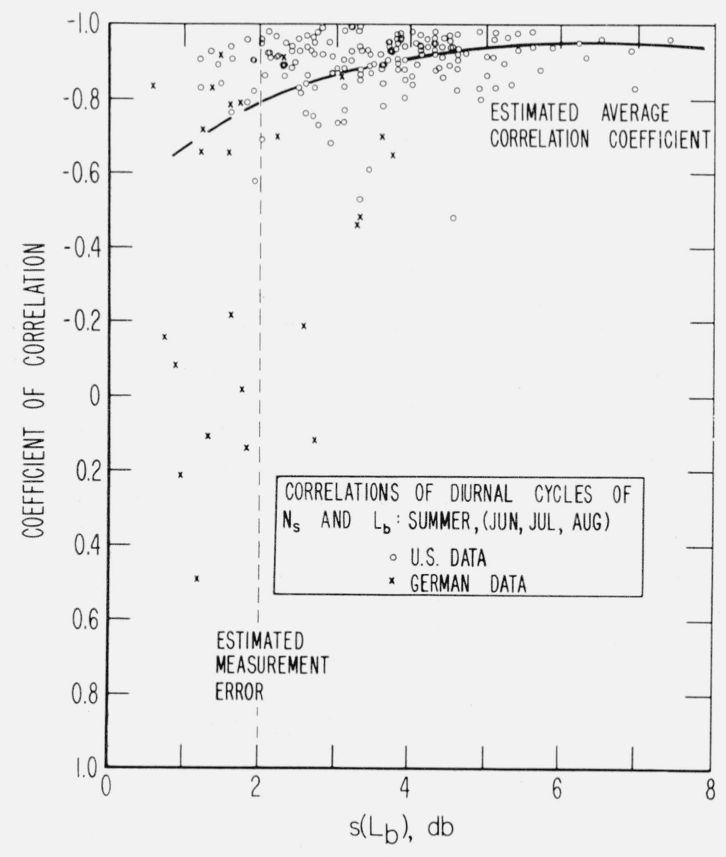

FiguRE 5. Correlation coefficients of diurnal cycles of monthly median $\mathrm{N}_{\mathrm{s}}$ and $\mathrm{L}_{\mathrm{b}}$ : summer (June, July, Aug.) versus the standard deviation of $\mathrm{L}_{\mathrm{b}}$.

of nighttime recordings and the summer time diurnal cycles.

For practical applications one wishes to determine the regression coefficient, $b$, in the leastsquares derived regression line

$$
L_{b}=b N_{s}+a .
$$

The regression coefficient gives the sensitivity of $L_{b}$ to a unit change in $N_{s}$. The intercept, $a$, is a function of path characteristics such as antenna heights, distance, and terrain. For practical applications the intercept is best obtained from available prediction processes such as those of Rice, Longley, and Norton [1959]. The regression coefficients for the seasonal cycles seemed sufficiently independent of propagation path characteristics that a simple average of $-0.18 \mathrm{db}$ per unit change in $N_{s}$ was adopted, figure 6 , by neglecting the values associated with $s\left(L_{b}\right)<2 \mathrm{db}$.

The regression coefficients associated with the diurnal cycle, however, appear to be better described in terms of distance and time of year. The diurnal regression coefficients for $s\left(L_{b}\right)>2 \mathrm{db}$ were plotted versus distance for each month of the year. A curve through the data points was determined visually. The scatter of points about the resultant curves was comparable to that of figure 6 . A comparison of the individual monthly curves revealed that several months could be combined so that only three curves are needed: winter (December-February), spring (March-May), summer-fall (June-November).
These curves are shown on figure 7. The peak of the summer-fall curves are near $200 \mathrm{~km}$ as compared to $175 \mathrm{~km}$ for the winter-time curves in keeping with the general extension of the radio horizon in the warmer months. [See for example the CCIR curves of $\Delta N / \mathrm{km},[1959 \mathrm{~b}]$.$] Although the summer$ peak is lower than the winter peak the observed diurnal range of $N_{s}$ is greater in the summer with resultant greater range of $L_{b}$.

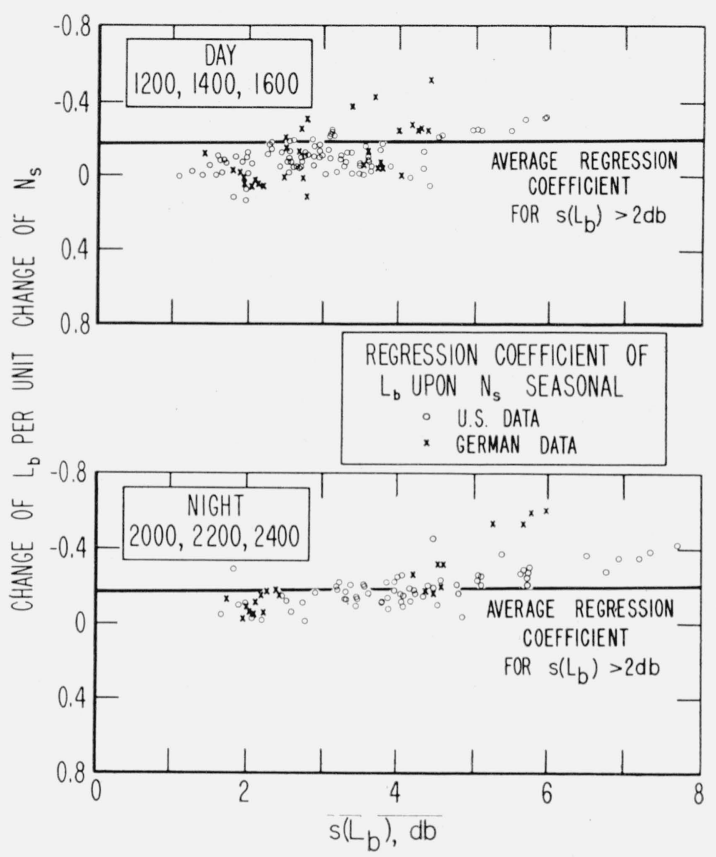

Figure 6. Regression coefficients of seasonal cycles of monthly median $\mathrm{L}_{\mathrm{b}}$ upon $\mathrm{N}_{\mathrm{s}}$ for both day and night versus the standard deviation of $\mathrm{L}_{\mathrm{b}}$.

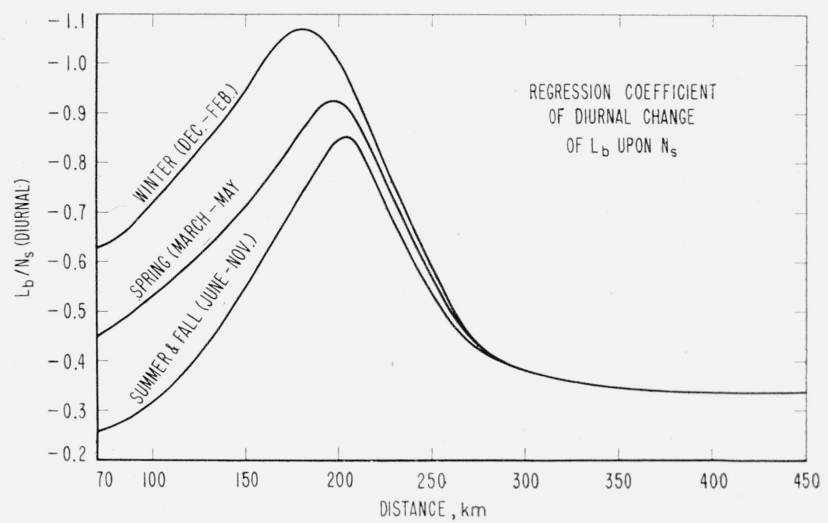

FIGURE 7. Variability of regression coefficient of diurnal change of monthly median $\mathrm{L}_{\mathrm{b}}$ upon $\mathrm{N}_{\mathrm{s}}$ versus both distance and month of year. 


\section{Within-Month Variation of Hourly Median}

\section{$\mathrm{L}_{\mathrm{b}}$}

The above observations suggest a basis for developing a method for estimating the within month variation of $L_{b}$ that might perhaps be eventually useful in practical prediction processes.

The value of the intercept in (1) could be obtained by a variety of existing prediction methods, but for the purpose of this demonstration it will be assumed to be identically the observed February monthly median value of $L_{b}$ for the hour 1400 for each radio path. The value of $L_{b}$ at 1400 for any other month is then

$$
L_{b}\left(M_{i}, 1400\right)=-0.18\left[N_{s}\left(M_{i}, 1400\right)\right.
$$

$$
(1 \leq i \leq 12)
$$

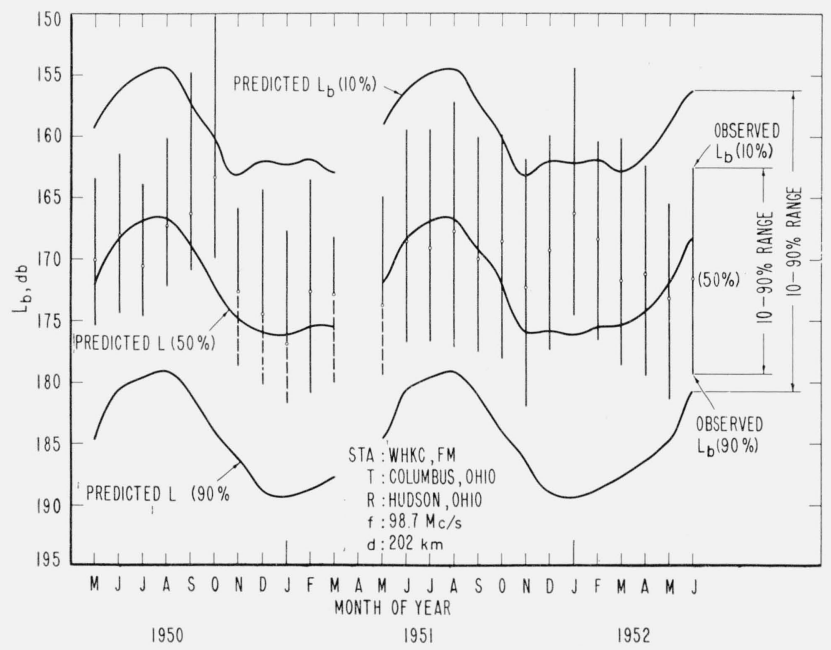

Figure 8. Comparison of observed 10-to-90 percent withinmonth variation of hourly median transmission loss with values predicted from eq (3) for WHKC-FM.

[Broadcast day: 0600-0100.]

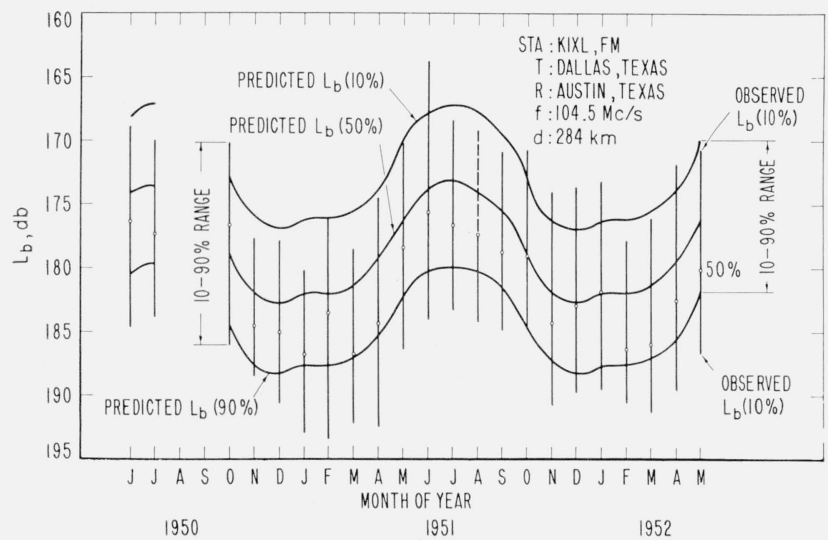

Figure 9. Comparison of observed 10-to-90 percent withinmonth variation of hourly median transmission loss with values predicted from eq (3) KIXL-FM.

[Broadcast day: $24 \mathrm{hr}$. where the notation $M_{i}$ indicates the month of the year. To obtain the value of $L_{b}$ at any hour, $h_{j}$, within any month one evaluates

$$
L_{b}\left(M_{i}, h_{j}\right)=L_{b}\left(M_{i}, \frac{1400)+}{b_{j}\left[N_{s}\left(M_{i}, h_{j}\right)-N_{s}\left(M_{i}, 1400\right)\right]}\right.
$$

$$
(1 \leq j \leq 24)
$$

where $b_{j}$ is the appropriate value of the regression coefficient obtained from figure 7. Equation (3) allows one to estimate the monthly median value of $L_{b}$ for any given hour of the day and month of the year. Equation (3) may also be used to estimate the within-month variation of individual hourly median $L_{b}$ by assuming that this variation is due to the superposition of the individual daily diurnal cycles of $L_{b}$. For any given path and month the regression coefficients in (3) are constant and one need only determine the desired range of withinmonth variation of $N_{s}$, insert this into eq (3) and then obtain an estimate of the expected withinmonth variation of $L_{b}$. Thus, for example, the insertion of the 10 to 90 percent within-month range of $N_{s}$ into (3) yields an estimate of the 10 to 90 percent within-month range of $L_{b}$. Examples of this procedure are given on figures 8 and 9 for the same two radio paths whose annual and diurnal cycles were shown in figure 1 . The predicted median within-month level of $L_{b}$ appears to follow that of the observed data. The predicted 10 to 90 percent ranges of $L_{b}$ are larger than the observed ranges for KIXL-FM and smaller than those of WHKC-FM. This is actually encouraging since one would wish a prediction process to bracket the observed values when applied to individual examples. Five U.S. radio paths were selected as a quantitative measure of the agreement between observed and predicted 10 to 90 percent ranges. These paths (numbers 3, $7,9,16$, and 23 of appendix 1 ) cover a wide range of climate and radio propagation path conditions. The predicted 10 to 90 percent ranges were calculated in two separate ways. First, the smoothed regression coefficients, called $b_{s m}$, hereafter, were obtained from figure 7 and used in conjunction with published long-term distributions of $N_{s}$ [Bean, Horn, and Ozanich, 1960] and, secondly, the observed regression coefficients for each path were used with the actual $N$ distributions for each month of radio record. The results are shown on figure 10 . Both methods of prediction agree within $5 \mathrm{db}$ at the 50 percent level but the total range is noticeably smaller from the $b_{s m}$ and long-term $N_{s}$ combination. One surmises that this is due, perhaps, to the similarity of space averaging of $N$ conditions by the radio waves traversing the entire radio path and the time averaging of the increased meteorological record used in the long-term distributions of $N$. Similar arguments may be applied to $b_{s m}$. The nine German paths also held the same conclusion. These data are shown for both the 50 to 90 percent range and the 10 to 50 percent range on figures 11 and 12 .

From the above one concludes the correlation of $L_{b}$ and $N_{s}$ : 
(1) increases with increasing variation of $L_{b}$ or $N_{s}$;

(2) is greater for seasonal cycles of the nighttime values of the variables than for the midday values;

(3) is greater for the diurnal cycles during the summer months than for those in the winter months.

Further, conclusions (1)-(3) indicate promise for a method of estimating the within-month variation of hourly median field strengths.

Although these conclusions are for a limited sample, one would expect those pertaining to the correlation coefficients to be generally observed. The development of a prediction method analogous to the above must carefully account for the complex sensitivity of $L_{b}$ to changes in $N_{s}$. This could include a consideration of season, climatic region, distance, and frequency.

One can perhaps see in the above analysis the roots of the controversy [Misme, 1960] over the utility of $N_{s}$ as a field strength predictor. If an experimenter had available transmission loss data for only the afternoon hours, he would conclude that the practical utility of the correlation is indeed suspect. The same would be true if his radio data were obtained in an area where the variation of $L_{b}$ was characteristically close to measurement error. This is apparently the case for western Europe since the German data on figures 2 to 5 tend to lie within the estimated measurement error.

One is encouraged in this view by the climatic behavior of $\mathrm{N}_{s}$. Since these correlations are presumably due to refractive effects, one would expect the correlation coefficients to be systematically greater the greater the range of $N_{s}$. The annual range of monthly mean values of $N_{s}$ is 10 to $15 N$ units for western Europe and $50 N$ units for the eastern United States [Bean and Horn, 1959]. The small range of monthly mean values in western Europe arises from the steady onshore flow of maritime air throughout the year while the large range of the eastern U.S. arises from the frequent intrusion of such diverse air masses as polar air in the winter and tropical air in the summer.

One may surmise that the marked distance dependence of regression coefficient is not independent of propagation mechanism. For example, it is commonly observed that the greatest range of VHF radio fields is observed beyond the radio horizon in the region where diffracted and scattered radio field strengths are of about equal magnitude. This is also a region where increased radio field strengths are frequently associated with low-level superrefractive layers and elevated reflecting layers. It is not unreasonable to associate the relatively large values of $b$ with a combination of sensitivity of diffracted field strengths to refractive changes plus occasional strong superrefraction. Well beyond the horizon, however, scattering is assumed to be the predominant cause of weak fields, and, since this mode of propagation is relatively constant in mean level, one assumes that the relatively low value of $b$ is due to the insensitivity of this mechanism to refraction changes.

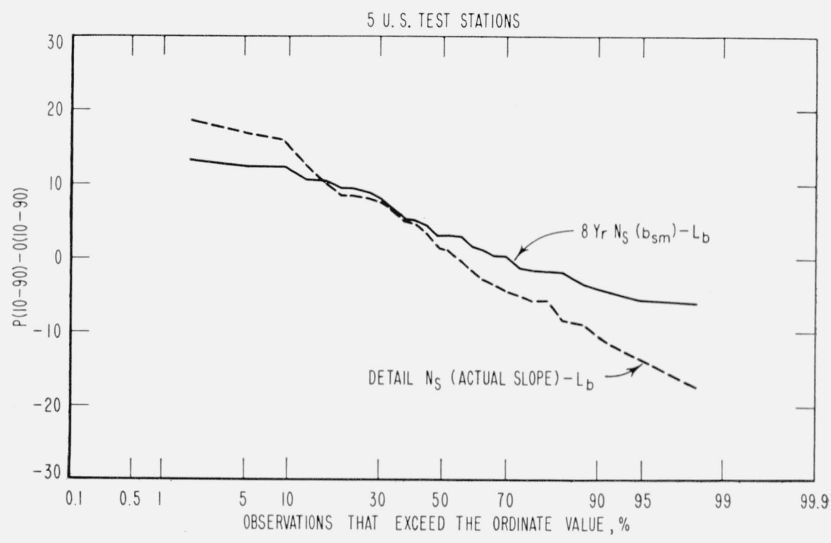

FIgURE 10. Cumulative probability distributions of predicted minus observed within-month 10-to-90 percent range of $\mathrm{L}_{\mathrm{b}}$ for 5 U.S. test paths.

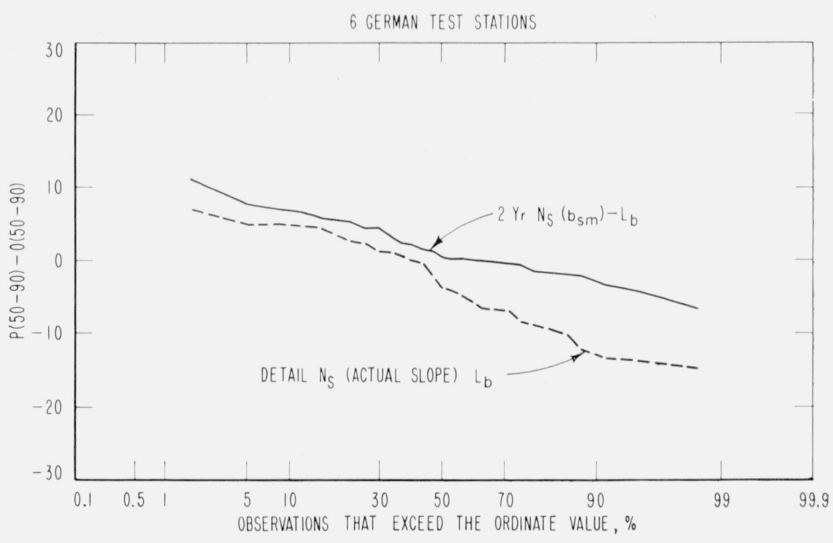

FIgure 11. Cumulative probability distributions of predicted minus observed within-month 50-to-90 percent range of $\mathrm{L}_{\mathrm{b}}$ for 6 German test paths.

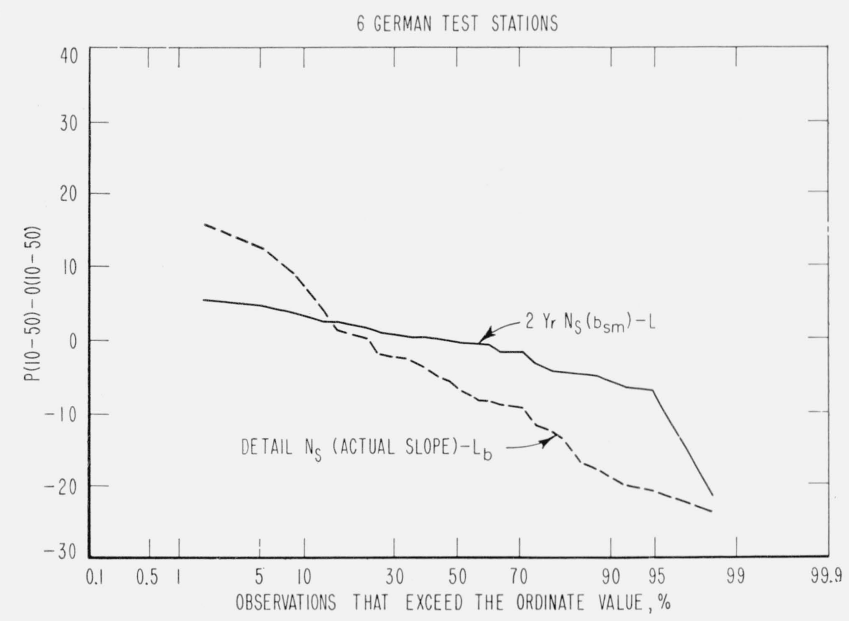

FIGURE 12. Cumulative probability distributions of predicted minus observed within-month 10-to-50 percent range of $\mathrm{L}_{\mathrm{b}}$ for 6 German test paths. 


\section{Analysis of Results}

The conclusions reached above are dependent upon the choice of statistical model. Although both variables are subject to observational errors, the standard regression analysis used assumes that the independent variable, $N_{s}$, is known exactly and that only the dependent variable, $L_{b}$, is in error. In practice this assumption assigns any error in $N_{s}$ to $L_{b}$. We shall examine this assumption.

The rms error in $N_{s}$ due to errors in meteorological measurements, $s\left(N_{s}\right)_{m}$, may be evaluated from the expression

$s\left(N_{s}\right)_{m}=\left\{\left(\frac{\partial N}{\partial t} \Delta T\right)^{2}+\left(\frac{\partial N}{\partial e} \Delta e\right)^{2}+\left(\frac{\partial N}{\partial P} \Delta P\right)^{2}\right\}^{1 / 2}$

by assuming that there is no correlation between the various errors of measurement. For normal conditions $\left(T=15{ }^{\circ} \mathrm{C}, \quad R H=60 \%, P=1013 \mathrm{mb}\right)$ $s\left(N_{s}\right)_{m}$ is about $1 N$ unit. There is an additional error in the mean arising from serial correlation of successive observations of $N_{s}$. The error in the long term mean value of $N_{s}$ is estimated from the expression

$$
s\left(\bar{N}_{s}\right)=\frac{s\left(N_{s}\right)}{\sqrt{j}}
$$

where $s\left(\bar{N}_{s}\right)$ indicates the error of the mean and $s\left(N_{s}\right)$ the standard deviation of the $p$ individual values used to determine $\overline{N_{s}}$. The effective number of independent observations (free of serial correlation) is $j$.

The value of $j$ is determined by examination of the serial correlation within the data. Examination of the data indicates it to be approximately described by

$$
r_{k}=(r)^{k}, k=1,2,3, \ldots, p,
$$

where $r_{k}$ is the serial correlation coefficient for the lag $k$. By assuming that

$$
r \equiv r_{1}
$$

the effective number of independent observations may be estimated as [Brooks and Carruthers, 1953]

$$
j=p \frac{1-r_{1}}{1+r_{1}}
$$

where $p$ is the total number of observed values of $N_{s}$. Even when so accounting for the effect of serial correlation upon the error of the mean it is seen from table 1 that this standard error will be less than 2.5 $N$ units. The important statistic,

$$
\frac{s^{2}\left(N_{s}\right)_{m}+s^{2}\left(\bar{N}_{s}\right)}{s^{2}\left(N_{s}\right)} 100 \%,
$$

is also listed in table 1 and is seen to be no more than 4 percent which is taken to be sufficiently small as to warrant the adoption of regression analysis for the present study.
The errors of observation of $L_{b}$ are unknown and could easily be smaller than the arbitrary value of $2 \mathrm{db}$ of standard error adopted here. Fortunately, however, practical applications require the regression coefficient,

$$
\frac{\text { covariance }\left(L_{b}, N_{s}\right)}{s^{2}\left(N_{s}\right)},
$$

\begin{tabular}{|c|c|c|c|c|c|c|}
\hline \multirow{2}{*}{ Station } & \multirow{2}{*}{$\stackrel{s\left(N_{8}\right)}{(N \text { units })}$} & \multirow{2}{*}{$r_{1}$} & \multicolumn{2}{|c|}{$s\left(\bar{N}_{s}\right)$} & \multirow{2}{*}{\multicolumn{2}{|c|}{$\frac{s^{2}\left(N_{s}\right)_{m}+s^{2}\left(\bar{N}_{s}\right)}{s^{2}\left(N_{s}\right)}$} $100 \%$} \\
\hline & & & $r=0$ & $r=r_{1}$ & & \\
\hline $\begin{array}{l}\text { Washington, D.C..... } \\
\text { Denver, Colorado } \\
\text { Tatoosh Is., Wash.... } \\
\text { San Diego, Calif...... }\end{array}$ & $\begin{array}{r}19.1 \\
14.1 \\
5.9 \\
9.7\end{array}$ & $\begin{array}{r}0.54 \\
.40 \\
.38 \\
.56\end{array}$ & $\begin{array}{r}1.30 \\
0.96 \\
.40 \\
.66\end{array}$ & $\begin{array}{l}2.4 \\
1.46 \\
0.62 \\
1.24\end{array}$ & $\begin{array}{l}\text { Percent } \\
1.8 \\
1.6 \\
3.9 \\
2.7\end{array}$ & \\
\hline
\end{tabular}

which is independent of errors in $L_{b}$ and thus is not affected by the arbitrary choice of a value of $s^{2}\left(L_{b}\right)$.

TABLE 1.-Effect of serial correlation upon the error in the long term mean values of $\mathrm{N}_{\mathrm{s}}$

(All data for May 1200 local time)

Note: Assuming that $s^{2}\left(N_{s}\right)_{m} \equiv 1 N$ unit and $r=r_{1}$.

Although the brief analysis above justifies the statistical treatment used in this study one is left with the question of the relative utility of $N_{s}$ as a predictor. A simple test was devised to shed light on this question. Those radio paths for which more than 1 yr of observations were available were broken into two parts (a) the first year of observation and (b) all subsequent years. The monthly mean values of $L_{b}$ from the first year were then correlated with the data of subsequent years. Monthly mean values of $N_{s}$ were also correlated with the radio data from the subsequent years. As before, correlations were performed on both seasonal and diurnal variations. The results of this comparison, shown in table 2, clearly

TABLE 2. Utility of $N_{\mathrm{s}}$ and $L_{\mathrm{b}}$ as predictors of variations of $L_{\mathrm{b}}$

Case I: Residual error of prediction of $L_{b}$ versus $L_{b}$

less than $L_{b}$ versus $N_{s+\ldots} \ldots$

Case II: Residual error of prediction of $L_{b}$ versus $N_{s}$ less than $L_{b}$ versus $L_{b}$

\begin{tabular}{r|r} 
Number of data sets \\
\hline $\begin{array}{c}\text { Diurnal } \\
\text { variations }\end{array}$ & $\begin{array}{c}\text { Seasonal } \\
\text { variations }\end{array}$ \\
\hline 16 & 16 \\
\hline 18 & 26 \\
\hline
\end{tabular}

Note: $\mathrm{L}_{b}$ data restricted to those cases where $s\left(L_{b}\right) \geq 2 \mathrm{db}$.

indicate that $\mathrm{N}_{\mathrm{s}}$ appears to be as useful a predictor of diurnal and seasonal variations of monthly median values of $\mathrm{L}_{\mathrm{b}}$ as radio measurements made over the actual radio path. This last observation, although derived from limited observations, has far-reaching implications for the communications engineer should it be found to be universally true.

The authors express their appreciation to Mr. C. M. Miller for his careful collation of the data used in this study and tireless verification of seemingly spurious data. 


\section{Appendix 1. Radio and Meteorological Data}

\begin{tabular}{|c|c|c|c|c|c|c|}
\hline Radio station and path & Meteorological station $\left(\mathrm{N}_{8}\right)$ & Frequency & Distance & $\theta$ & $\begin{array}{c}\text { Broadcast } \\
\text { day }\end{array}$ & $\begin{array}{l}\text { Period of } \\
\text { record }\end{array}$ \\
\hline 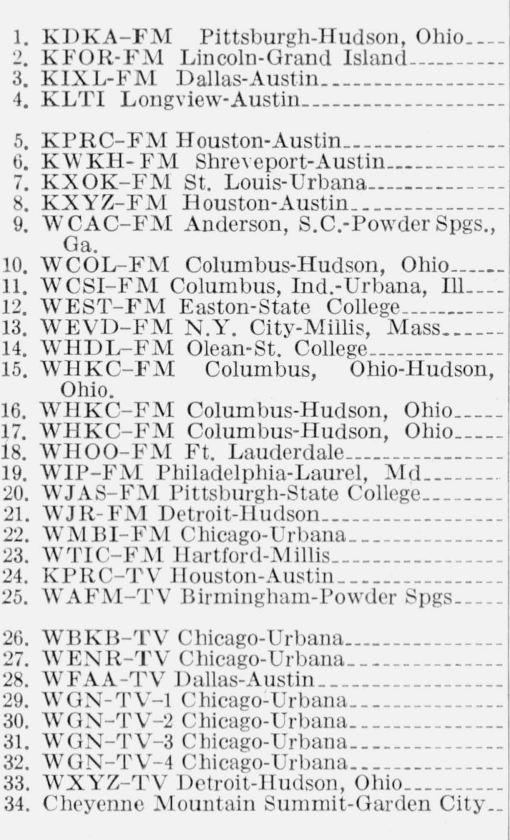 & 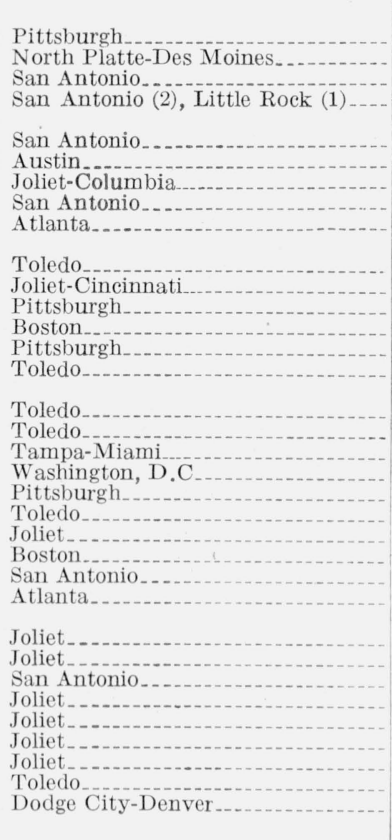 & $\begin{array}{r}M c / s \\
92.9 \\
102.9 \\
104.5 \\
105.9 \\
102.9 \\
94.5 \\
93.7 \\
96.5 \\
101.1 \\
92.3 \\
93.7 \\
107.9 \\
107.5 \\
95.7 \\
98.7 \\
98.7 \\
98.7 \\
96.5 \\
93.3 \\
99.7 \\
96.3 \\
95.5 \\
56.5 \\
59.75 \\
215.75 \\
71.75 \\
179.75 \\
185.75 \\
191.75 \\
191.75 \\
191.5 \\
191.75 \\
179.75 \\
100.0\end{array}$ & \begin{tabular}{l|}
$k m$ \\
155.6 \\
150.0 \\
283.1 \\
365.6 \\
\\
237.8 \\
446.4 \\
235.8 \\
237.8 \\
205.2 \\
195.0 \\
223.7 \\
224.2 \\
197.9 \\
146.1 \\
201.2 \\
201.0 \\
201.2 \\
299.0 \\
167.5 \\
188.4 \\
181.5 \\
202.8 \\
129.9 \\
229.6 \\
196.3 \\
203.7 \\
203.2 \\
281.8 \\
204.4 \\
204.4 \\
204.4 \\
204.4 \\
179.9 \\
364.5
\end{tabular} & $\begin{array}{c}m r \\
12.2 \\
14.6 \\
32.4 \\
40.4 \\
\\
21.0 \\
47.4 \\
19.3 \\
20.6 \\
19.8 \\
20.1 \\
20.9 \\
36.7 \\
28.1 \\
29.5 \\
19.4 \\
19.4 \\
19.4 \\
27.4 \\
12.0 \\
30.4 \\
10.4 \\
16.1 \\
16.3 \\
18.3 \\
22.3 \\
16.4 \\
16.4 \\
34.6 \\
17.0 \\
16.8 \\
16.5 \\
17.1 \\
10.3 \\
30.4\end{array}$ & $\begin{array}{r}0900-2300 \\
1500-0000 \\
24 \mathrm{hr} \\
0800-2300 \\
0600-0000 \\
0500-0100 \\
0600-2000 \\
0700-2300 \\
0600-0000 \\
0700-0100 \\
0600-2300 \\
0600-0000 \\
0700-0000 \\
0600-2300 \\
0600-0100 \\
\\
0600-0100 \\
0600-0100 \\
0800-0000 \\
0900-0000 \\
0700-0100 \\
0700-0000 \\
0600-2200 \\
0400-0000 \\
0700-0000 \\
1000-0000 \\
\\
0700-0000 \\
0900-0000 \\
1200-2300 \\
0900-0100 \\
6900-0100 \\
0900-0100 \\
0900-0100 \\
0700-0100 \\
24 \text { hr }\end{array}$ & 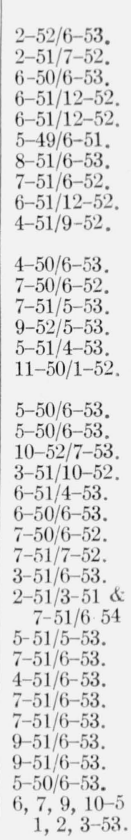 \\
\hline
\end{tabular}

German Stations
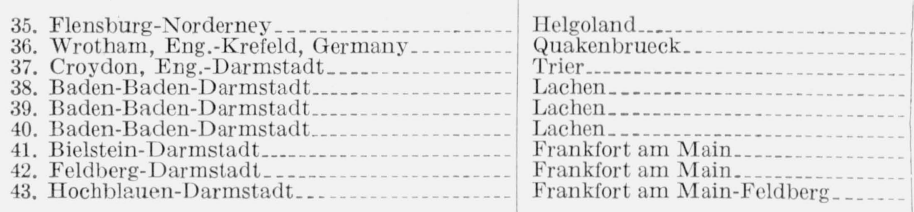

93.0
93.7
191.27
6825.0
400.0
400.0
90.65
9339.5
516.0

\begin{tabular}{c|c|}
187 & 13.9 \\
434 & 38.0 \\
638 & $-\cdots-$ \\
125.0 & $-\cdots-$ \\
125.6 & $-\cdots \cdot$ \\
125.0 & $-\cdots-$ \\
227.8 & 28.0 \\
42.0 & $-\cdots-$ \\
42 & $\cdots-.-$
\end{tabular}

\begin{tabular}{r|l}
$0600-2300$ & $4-54 / 1-55$. \\
$0800-2300$ & $11-55 / 5-57$. \\
$1100-2300$ & $11-57 / 9-58$. \\
$24 \mathrm{hr}$ & $9-58 / 6-59$. \\
$24 \mathrm{hr}$ & $3-59 / 11-59$. \\
$24 \mathrm{hr}$ & $3-59 / 11-59$. \\
$24 \mathrm{hr}$ & $7-57 / 9-58$. \\
$24 \mathrm{hr}$ & $10-58 / 12-59$. \\
$24 \mathrm{hr}$ & $6-59 / 12-59$.
\end{tabular}

\section{References}

Bean, B. R., Some meteorological effects on scattered radio waves, Trans. IRE CS-4, 32-38 (1956).

Bean, B. R. and J. D. Horn, The radio refractive index near the ground, J. Research NBS 63D (Radio Prop.), 259-273 (Nov.-Dec. 1959).

Brooks, C. E. P., and N. Carruthers, Handbook of Statistical Methods in Meteorology (Her Majesty's Stationery Office, 1953).

International Radio Consultative Committee, Documents of the IX Plenary Assembly, Los Angeles, Vol. III, Report No. 138, Sec. 7, Accuracy and repeatability of the measurements (1959a).

International Radio Consultative Committee, Documents of the IX Plenary Assembly, Los Angeles, Vol. III, Report No. 147 (1959b).

Misme, P., Quelques aspects de la radiometeorologie et de la radioclimatologie, Ann. Telecomm. 14, Nos. 11-12, 266-273 (Nov.-Dec. 1960).
Moler, W. F., and W. A. Arvola, Vertical motion in the atmosphere and its effect on $\mathrm{VHF}$ radio signal strength, Trans. Am. Geophys. Union 37, 399 (Aug. 1956).

Moler, W. F., and D. B. Holden, Tropospheric scatter propagation and atmospheric circulations, J. Research NBS 64D (Radio Prop.), No. 1, 81-93 (Jan.-Feb. 1960).

Pickard, G. W., and H. T. Stetson, Comparison of tropospheric reception at $44.1 \mathrm{Mc}$ with 92.1 Mc over the 167 mile path of Alpine, New Jersey, to Needham, Massachusetts, Proc. IRE 38, 1450 (1950a).

Pickard, G. W., and H. T. Stetson, Comparison of tropospheric reception, J. Atmospheric and Terrest. Phys. 1, $32(1950 \mathrm{~b})$.

Rice, P. L., A. Longley, and K. A. Norton, Prediction of the cumulative distribution with time of ground wave and tropospheric wave transmission loss, part I, The prediction formula, NBS Tech. Note (July 1959).

Snedecor, G. W., Statistical Methods, p. 152 (Iowa State College Press, Ames, Iowa,1946).

(Paper 66D5-219) 